\title{
Fatores influenciadores da divulgação de informação e do acesso à informação dos municípios
}

\author{
Factors influencing the information disclosure and \\ access to information in municipalities
}

Francisca TEJEDO-ROMERO' (D) 0000-0002-2600-9826
Joaquim Filipe Ferraz Esteves ARAUJO2 (iD) 0000-0001-8531-6036

\section{Resumo}

\begin{abstract}
A transparência e o acesso à informação são importantes para o escrutínio público, a participação e a responsabilidade, contribuindo para a confiança dos cidadãos no governo. Para aumentar o acesso à informação pública, os governos locais têm recorrido à transparência ativa através da divulgação de informação pública nos seus websites, com acesso livre e aberto. Este estudo analisa a influência de fatores socioeconômicos e políticos na gestão das políticas públicas de transparência ativa nos municípios portugueses. O estudo utiliza a metodologia de dados de painel, que ainda não foi empregada para examinar a transparência municipal ativa em Portugal, testando empiricamente os fatores que impactam a divulgação da informação pública, valendo-se do índice de transparência como um proxy. Foram encontradas evidências empíricas em relação aos fatores políticos e socioeconômicos que influenciaram o nível de transparência municipal. Uma vez que os estudos sobre o caso português são escassos, esta pesquisa contribui para a compreensão das respostas dos municípios às pressões da sociedade por mais transparência.
\end{abstract}

Palavras-chave: Divulgação de informação. Governos locais. Transparência.

\begin{abstract}
Transparency and access to information are important for public scrutiny, participation and accountability, contributing to citizens' confidence in the local government. To increase access to public information, local governments resorted to active transparency through the dissemination of public information on their websites, in a free and open manner. This study reviews the influence of socioeconomic and political factors in the management of active transparency of public policies in Portuguese municipalities. The study uses the panel data methodology, which has not yet been used to review active municipal transparency in Portugal, empirically testing the factors that influence the disclosure of public information, using the transparency index as a proxy. Empirical evidence was found regarding the political and socioeconomic factors that have influenced the level of municipal transparency. Since studies regarding Portuguese cases are scarce, this investigation contributes to the understanding of the municipalities' responses to society's pressures for more transparency.
\end{abstract}

Keywords: Information disclosure. Local governments. Transparency.

\footnotetext{
1 Universidad de Castilla-La Mancha, Departamento de Administración de Empresas. Plaza de la Universidad, 1, 02071, Albacete, España. Correspondência para/Correspondence to: F. TEJEDO-ROMERO. E-mail:<francisca.tejedo@uclm.es>.

2 Universidade do Minho, Escola de Economia e Gestão, Centro de Investigação em Ciência Política. Braga, Portugal.

Apoio: Fundação para a Ciência e Tecnologia e Ministério da Educação e Ciência através do Centro de Investigação em Ciência Política (UIDB/ CPO/00758/2020).

Recebido em 2 de junho de 2020, reapresentado em 26 de outubro de 2020 e aprovado em 2 de dezembro de 2020.
}

Como citar este artigo/How to cite this article

Tejedo-Romero, F.; Araujo, J. F. F. E. Fatores influenciadores da divulgação de informação e acesso à informação dos municípios. Transinformação, v. 33 , e200038, 2021. https://doi.org/10.1590/2318-0889202133e200038 


\section{Introdução}

A facilidade de acesso à informação abriu as organizações públicas ao escrutínio dos cidadãos, contribuindo para a melhoria da confiança em relação às atividades e ações desenvolvidas na Administração Pública (Styles; Tennyson, 2007; Birchall, 2015; Moreno-Sardà; Molina-Rodríguez-Navas; Simelio-Solà, 2017; Piñeiro-Naval; Mangana; Serra, 2018). Vários países comprometeram-se com promover iniciativas de transparência nas organizações públicas, procurando tornar a Administração Pública mais aberta, responsável e receptiva aos cidadãos (García-Tabuyo; Saez-Martin; Caba-Perez, 2017; Rebolledo; Zamora-Medina; Rodríguez-Virgili, 2017; Serrano-Cinca; Muñoz-Soro, 2019; Wasike, 2020). A transparência e a abertura das atividades da Administração Pública ao escrutínio público são iniciativas que vão nesse sentido (Lowatcharin; Menifield, 2015; Robles-López; Zamora-Medina, 2020). Elas são consideradas uma condição essencial para melhorar os resultados dos governos e a eficácia gestionária, uma característica fundamental da boa governação (Piotrowski, 2007; Moreno-Sardà; Molina-Rodríguez-Navas; SimelioSolà, 2017; Curto-Rodríguez, 2020).

No entanto, o desafio de disponibilizar informações aos cidadãos vai além do mero fornecimento de informações de forma passiva, a pedido dos cidadãos e a critério dos governos. Os governos têm buscado divulgar informação de modo mais ativo, com organizações públicas que fornecem informações compreensíveis para os cidadãos e outros stakeholders (Beltrán-Orenes; Martínez-Pastor, 2016; García-Tabuyo; Saez-Martin; Caba-Perez, 2017; Manfredi-Sánchez, 2017).

Portugal é um estudo de caso interessante porque o acesso à informação pública é um direito constitucional desde 1989 (n² do Art. 268 da Constituição da República Portuguesa) (Portugal, 1989). A Constituição dá aos cidadãos o direito de acesso à informação pública, estabelecendo o princípio do livre acesso aos arquivos e documentos da Administração Pública através da consulta ou da reprodução pelo cidadão comum, independentemente da invocação de um interesse ou motivo. Inicialmente não havia obrigação legal de os órgãos governamentais ou entidades públicas informarem os cidadãos sobre suas atividades. Esse direito só foi regulamentado posteriormente, pela Lei de Acesso aos Documentos Administrativos - Lei n 65/93, de 26 de agosto (Portugal, 1993). A lei estabelece as condições para ter acesso a informações administrativas, o que configura uma forma de transparência "passiva". Até então as organizações públicas respondiam de maneira reativa aos pedidos de informação dos cidadãos (Mendes et al., 2016; Tavares; Cruz, 2020).

A aprovação da Lei de Transparência em 2016 alterou a forma e as condições de acesso às informações administrativas. As alterações introduzidas pela lei modificaram substancialmente o modelo de transparência "passiva", introduzindo um modelo de transparência "ativa". A lei determinou que as informações sobre as operações da Administração Pública e o controle das atividades administrativas devem ser divulgadas regularmente, em um formato aberto e legível. Ainda, as informações devem ser divulgadas nos portais das organizações públicas com acesso livre e aberto.

É ao nível municipal que as interações entre cidadãos e governos são cruciais para a democracia representativa local. A crescente interação dos municípios com os cidadãos e a preocupação com o bem-estar destes podem ser reforçadas por iniciativas para promover a transparência. Este artigo contribui para a literatura sobre transparência testando empiricamente um quadro teórico que explica os fatores que influenciam a transparência nos municípios portugueses. Trata-se de um estudo longitudinal que abrange um período de 4 anos compreendido entre 2013 e 2016.

Poucas pesquisas foram produzidas para o caso português (Mendes et al., 2016; Piñeiro-Naval; Mangana; Serra, 2018; Tavares; Cruz, 2020). Este estudo é um contributo para entender as respostas dos municípios às pressões dos cidadãos por mais transparência. O quadro empírico centra-se nos fatores que influenciam a transparência, com uso de dados de painel, apresentando duas hipóteses explicativas: fatores socioeconômicos e fatores políticos. Os dados foram recolhidos para a totalidade dos municípios portugueses a partir de fontes oficiais. 
A transparência está relacionada com a disponibilidade e o acesso a informações sobre as organizações governamentais (Manfredi-Sánchez, 2017; Garrido-Rodríguez; López-Hernández; Zafra-Gómez, 2019; Robles-López; Zamora-Medina, 2020). Refere-se, por um lado, ao acesso à informação por parte dos cidadãos e outros stakeholders e à sua utilização (lado da procura da transparência) e, por outro lado, à disponibilidade de informação por parte das organizações públicas (lado da oferta da transparência).

A literatura sobre a transparência (Meijer, 2013; Bauhr; Grimes, 2014; Moreno-Sardà; Molina-Rodríguez-Navas; Simelio-Solà, 2017) defende que a divulgação de informação sobre a eficácia política, administrativa e gestionária pode contribuir para a melhoria da boa governação (Piotrowski, 2007; Brusca; Manes; Aversano, 2016; Balaguer-Coll; Brun-Martos, 2019; Wasike, 2020). A divulgação da informação permite aos cidadãos e outros stakeholders monitorizar e avaliar o desempenho das organizações públicas (Grimmelikhuijsen; Welch, 2012; Meijer, 2013; Piñeiro-Naval; Mangana; Serra, 2018; Curto-Rodríguez, 2020), tornando mais transparente as suas atividades (Beltrán-Orenes; Martínez-Pastor, 2016; Rebolledo; Zamora-Medina; Rodríguez-Virgili, 2017; Navarro; Alcaraz; Ortiz, 2018).

A forma como a informação é divulgada e como funciona a transparência nas organizações varia entre os sistemas administrativos. Em alguns países, a informação é difundida de modo proativo, com organizações públicas atuando ativamente na divulgação de informação que é compreensível aos stakeholders (García-Tabuyo; Saez-Martin; Caba-Perez, 2017; Serrano-Cinca; Muñoz-Soro, 2019; Curto-Rodríguez, 2020). Em outros países, a informação está disponível mediante a solicitação dos cidadãos. Este é um modo de transparência "passiva", em que as organizações públicas respondem de forma reativa à procura externa, independentemente de como a informação está acessível.

Para efeito deste estudo, a transparência está relacionada com a informação divulgada de forma proativa (lado da oferta de transparência), considerando-se os municípios "ativos" no fornecimento de informação compreensível para os cidadãos e outros stakeholders (Bauhr; Grimes, 2014; Moreno-Sardà; Molina-Rodríguez-Navas; Simelio-Solà, 2017).

\section{Fatores influenciadores da transparência}

As pesquisas sobre a transparência salientam a importância das condições socioeconômicas e políticas como fatores determinantes da transparência dos governos centrais e locais (Gandía; Archidona, 2008; Pina et al., 2010; Guillamón et al., 2011; Grimmelikhuijsen; Welch, 2012; Albalate, 2013; Caamaño-Alegre et al., 2013; Arapis; Reitano, 2018; Gesuele et al., 2018; Tejedo-Romero; Araujo, 2018; Tavares; Cruz, 2020). Entre os fatores identificados na literatura, destacam-se o acesso dos cidadãos à Internet (Gandía; Archidona, 2008; Pina et al., 2010; Caba-Pérez; Rodríguez-Bolívar; López-Hernández, 2014; Arapis; Reitano, 2018; Navarro; Alcaraz; Ortiz, 2018; Tejedo-Romero; Araujo, 2018), a riqueza dos municípios (Gandía; Archidona, 2008; Guillamón et al., 2011; Albalate, 2013; Gesuele et al., 2018), a independência financeira (Guillamón et al., 2011; Gesuele et al., 2018; Tavares; Cruz, 2020), o nível da dívida pública (Guillamón et al., 2011; Caamaño-Alegre et al., 2013; Caba-Pérez; Rodríguez-Bolívar; López-Hernández, 2014; Arapis; Reitano, 2018; Gesuele et al., 2018; Navarro; Alcaraz; Ortiz, 2018), a participação eleitoral (Guillamón et al., 2011; Albalate, 2013; Caamaño-Alegre et al., 2013) e a ideologia política (Guillamón et al., 2011; Grimmelikhuijsen; Welch, 2012; Albalate, 2013; Caamaño-Alegre et al., 2013; Tejedo-Romero; Araujo, 2018). Ainda, Vicente, Benito e Bastida (2013) e Cuadrado-Ballesteros (2014) consideram a influência dos aspectos eleitorais na transparência, entre outros.

Os resultados das pesquisas prévias, como já referido, indicam que a transparência depende de fatores socioeconômicos e políticos (Albalate, 2013; Tejedo-Romero; Araujo, 2018). No entanto, ainda há ambiguidade nos resultados, o que limita a consistência das conclusões (Cucciniello; Porumbescu; Grimmelikhuijsen, 2017). Como se pode observar no Quadro 1, os resultados das pesquisas realizadas sobre os fatores socioeconômicos e políticos que influenciam a transparência reforçam a ideia da inconsistência desses fatores, pois não apresentam um comportamento uniforme nos estudos desenvolvidos. 
Quadro 1 - Estudos empíricos sobre fatores que influenciam a transparência.

\begin{tabular}{|c|c|c|c|c|}
\hline \multirow{2}{*}{ Autores } & \multirow{2}{*}{ Amostra e período } & \multirow{2}{*}{ Informação } & \multicolumn{2}{|c|}{ Relação entre os fatores e a transparência } \\
\hline & & & Fatores socioeconômicos & Fatores políticos \\
\hline $\begin{array}{l}\text { Tavares; Cruz } \\
\text { (2020) }\end{array}$ & $\begin{array}{l}278 \text { municípios } \\
\text { portugueses } \\
(2013)\end{array}$ & $\begin{array}{l}\text { Informação obtida } \\
\text { de Transparência, } \\
\text { Integridade, Associação } \\
\text { Cívica-Portugal }\end{array}$ & $\begin{array}{l}\text { Autonomia Financeira (+) } \\
\text { Desemprego (-) } \\
\text { Envelhecimento da População (-) } \\
\text { Capacidade de Tecnologias de } \\
\text { Informação (sem evidências) } \\
\text { População (sem evidências) }\end{array}$ & $\begin{array}{l}\text { Gênero do Presidente (+) } \\
\text { Competição Eleitoral (+) } \\
\text { Ideologia Política (sem } \\
\text { evidências) } \\
\text { Idade do Presidente (sem } \\
\text { evidências) } \\
\text { Presidentes com Estudos } \\
\text { Superiores (sem evidências) }\end{array}$ \\
\hline $\begin{array}{l}\text { Arapis; Reitano } \\
\text { (2018) }\end{array}$ & $\begin{array}{l}59 \text { países de várias } \\
\text { partes do mundo, } \\
\text { incluindo Portugal } \\
\text { (2006 a 2012) }\end{array}$ & $\begin{array}{l}\text { Informação fiscal } \\
\text { obtida da International } \\
\text { Budget Partnership }\end{array}$ & $\begin{array}{l}\text { Saldo Orçamental (+) } \\
\text { Receita de Petróleo (-) } \\
\text { Ajuda Externa (+) } \\
\text { Liberdade de Informação (+) } \\
\text { Origem Legal (+) } \\
\text { Tamanho do Setor Público (+) } \\
\text { Dívida Bruta (sem evidências) } \\
\text { Depleção Mineral (sem evidências) } \\
\text { Utilização da Internet (sem } \\
\text { evidências) } \\
\text { Recessão (sem evidências) }\end{array}$ & $\begin{array}{l}\text { Grau de Democracia (-) } \\
\text { Competição Política (sem } \\
\text { evidências) }\end{array}$ \\
\hline $\begin{array}{l}\text { Gesuele et al. } \\
\text { (2018) }\end{array}$ & $\begin{array}{l}287 \text { municípios } \\
\text { italianos e } \\
\text { espanhóis } \\
(2013)\end{array}$ & $\begin{array}{l}\text { Informação divulgada } \\
\text { nas páginas web dos } \\
\text { municípios }\end{array}$ & $\begin{array}{l}\text { Visibilidade na Internet (+) } \\
\text { Riqueza }(+) \\
\text { Alavanca (+) } \\
\text { Interesse da Mídia (sem evidências) } \\
\text { Autonomia Financeira (sem } \\
\text { evidências) }\end{array}$ & $\begin{array}{l}\text { Ideologia Política (sem } \\
\text { evidências) } \\
\text { Gênero do Presidente do } \\
\text { Município (sem evidências) }\end{array}$ \\
\hline $\begin{array}{l}\text { Navarro; Alcaraz; } \\
\text { Ortiz } \\
(2018)\end{array}$ & $\begin{array}{l}91 \text { municípios } \\
\text { grandes de nove } \\
\text { países europeus: } \\
\text { anglo-saxônicos } \\
\text { (Irlanda e Reino } \\
\text { Unido), nórdicos } \\
\text { (Finlândia, Noruega, } \\
\text { Suécia, Dinamarca } \\
\text { e Holanda) e sul da } \\
\text { Europa (Portugal e } \\
\text { Espanha) } \\
\text { (2015) }\end{array}$ & $\begin{array}{l}\text { Informação sobre } \\
\text { sustentabilidade obtida } \\
\text { nas páginas web dos } \\
\text { municípios }\end{array}$ & $\begin{array}{l}\text { População (+) } \\
\text { Dívida (+) } \\
\text { População Dependente (sem } \\
\text { evidências) } \\
\text { População Imigrante (sem } \\
\text { evidências) } \\
\text { Densidade Populacional (sem } \\
\text { evidências) } \\
\text { Nível de Educação (sem evidências) } \\
\text { Acesso à Internet (sem evidências) } \\
\text { Rendimento Médio Disponível (sem } \\
\text { evidências) } \\
\text { Desemprego (sem evidências) } \\
\text { Excedente/Déficit Orçamental (sem } \\
\text { evidências) } \\
\text { Autonomia Financeira (sem } \\
\text { evidências) } \\
\text { Pressão Fiscal (sem evidências) }\end{array}$ & $\begin{array}{l}\text { Idade da Lei de Transparência } \\
(-) \\
\text { Competição Política (sem } \\
\text { evidência) }\end{array}$ \\
\hline $\begin{array}{l}\text { Piñeiro-Naval; } \\
\text { Mangana; Serra } \\
\text { (2018) }\end{array}$ & $\begin{array}{l}308 \text { municípios } \\
\text { portugueses } \\
(2017)\end{array}$ & $\begin{array}{l}\text { Qualidade da } \\
\text { informação divulgada } \\
\text { nas páginas web dos } \\
\text { municípios }\end{array}$ & $\begin{array}{l}\text { População }(+) \\
\text { Orçamento }(+) \\
\text { Poder Aquisitivo }(+) \\
\text { Desenvolvimento Tecnológico do } \\
\text { Município }(+)\end{array}$ & - \\
\hline $\begin{array}{l}\text { Tejedo-Romero; } \\
\text { Araújo (2018) }\end{array}$ & $\begin{array}{l}100 \text { maiores muni- } \\
\text { cípios espanhóis } \\
\text { (2008 e 2014) }\end{array}$ & $\begin{array}{l}\text { Informação obtida da } \\
\text { Transparência Interna- } \\
\text { cional Espanha }\end{array}$ & $\begin{array}{l}\text { Tamanho da População (+) } \\
\text { Tecnologias de Informação (+) } \\
\text { Pressão Fiscal (+) }\end{array}$ & $\begin{array}{l}\text { Rivalidade Política }(+) \\
\text { Ideologia Política }(+) \\
\text { Efeito do Partido Regional } \\
\text { (sem evidências) }\end{array}$ \\
\hline $\begin{array}{l}\text { Brusca; Manes; } \\
\text { Aversano } \\
\text { (2016) }\end{array}$ & $\begin{array}{l}46 \text { municípios } \\
\text { italianos e } 59 \\
\text { municípios } \\
\text { espanhóis com } \\
\text { mais de } 100.000 \\
\text { habitantes } \\
\text { (2008 a 2011) }\end{array}$ & $\begin{array}{l}\text { Informação sobre } \\
\text { sustentabilidade obtida } \\
\text { das páginas web dos } \\
\text { municípios }\end{array}$ & $\begin{array}{l}\text { Variação nas Despesas (+) } \\
\text { Variação na Despesa Total (+) } \\
\text { Variação na Receita Total (+) } \\
\text { Pressão Fiscal (+) } \\
\text { Variação no Nível de Endividamento } \\
(+)\end{array}$ & - \\
\hline
\end{tabular}


Quadro 1 - Estudos empíricos sobre fatores que influenciam a transparência.

\begin{tabular}{|c|c|c|c|c|}
\hline \multirow{2}{*}{ Autores } & \multirow{2}{*}{ Amostra e período } & \multirow{2}{*}{ Informação } & \multicolumn{2}{|c|}{ Relação entre os fatores e a transparência } \\
\hline & & & Fatores socioeconômicos & Fatores políticos \\
\hline $\begin{array}{l}\text { Mendes et al. } \\
\text { (2016) }\end{array}$ & $\begin{array}{l}308 \text { municípios } \\
\text { portugueses } \\
(2013)\end{array}$ & $\begin{array}{l}\text { Informação recolhida } \\
\text { das páginas web dos } \\
\text { municípios }\end{array}$ & $\begin{array}{l}\text { População (+) } \\
\text { Receitas (-) } \\
\text { Visibilidade da Página Web (sem } \\
\text { evidências) }\end{array}$ & $\begin{array}{l}\text { Competição Política (sem } \\
\text { evidências) }\end{array}$ \\
\hline $\begin{array}{l}\text { Caba-Pérez; } \\
\text { Rodríguez-Bolívar; } \\
\text { López-Hernández } \\
\text { (2014) }\end{array}$ & $\begin{array}{l}30 \text { países da OCDE, } \\
\text { incluindo Portugal } \\
\text { (2013) }\end{array}$ & $\begin{array}{l}\text { Informação financeira } \\
\text { obtida das páginas web } \\
\text { dos países da OCDE }\end{array}$ & $\begin{array}{l}\text { Dívida Total (+) } \\
\text { Pressão Fiscal (sem evidências) } \\
\text { Nível de Educação (sem evidências) } \\
\text { População (sem evidências) } \\
\text { Acesso à Internet (sem evidências) } \\
\text { Riqueza Econômica (sem evidências) }\end{array}$ & $\begin{array}{l}\text { Competição Política (+) } \\
\text { Tipo de Governo (sem } \\
\text { evidências) }\end{array}$ \\
\hline $\begin{array}{l}\text { Cuadrado-Ballesteros } \\
\text { (2014) }\end{array}$ & $\begin{array}{l}110 \text { maiores } \\
\text { municípios espanhóis } \\
\text { (2008 a 2010) }\end{array}$ & $\begin{array}{l}\text { Informação recolhida } \\
\text { da Transparência } \\
\text { Internacional Espanha }\end{array}$ & $\begin{array}{l}\text { Endividamento (sem evidências) } \\
\text { Desemprego (-) } \\
\text { Riqueza (+) } \\
\text { Situação Geográfica (sem evidências) }\end{array}$ & $\begin{array}{l}\text { Ciclo Eleitoral (-) } \\
\text { Ideologia Política (sem } \\
\text { evidências) } \\
\text { Competição Política (sem } \\
\text { evidências) }\end{array}$ \\
\hline $\begin{array}{l}\text { Albalate } \\
\text { (2013) }\end{array}$ & $\begin{array}{l}100 \text { maiores } \\
\text { municípios espanhóis } \\
\text { (2010) }\end{array}$ & $\begin{array}{l}\text { Informação obtida } \\
\text { da Transparência } \\
\text { Internacional Espanha }\end{array}$ & $\begin{array}{l}\text { População (+) } \\
\text { Turismo (-) } \\
\text { Género (sem evidências) } \\
\text { Envelhecimento da População (sem } \\
\text { evidências) } \\
\text { Dívida (sem evidências) } \\
\text { Orçamento (sem evidências) } \\
\text { Capital (sem evidências) } \\
\text { Desemprego (sem evidências) } \\
\text { Atividade Econômica (sem evidências) }\end{array}$ & $\begin{array}{l}\text { Competição Política (+) } \\
\text { Ideologia Política (+) } \\
\text { Participação Eleitoral (sem } \\
\text { evidências) }\end{array}$ \\
\hline $\begin{array}{l}\text { Caamaño-Alegre } \\
\text { et al. } \\
\text { (2013) }\end{array}$ & $\begin{array}{l}33 \text { municípios } \\
\text { galegos (Espanha) } \\
(2008)\end{array}$ & $\begin{array}{l}\text { Informação recolhida } \\
\text { com base em um } \\
\text { inquérito }\end{array}$ & $\begin{array}{l}\text { Desemprego (-) } \\
\text { Saldo Fiscal (+) } \\
\text { Despesas Municipais sobre o PIB } \\
\text { Municipal (-) } \\
\text { Dívida (sem evidências) } \\
\text { Pressão Fiscal (sem evidências) } \\
\text { População (sem evidências) }\end{array}$ & $\begin{array}{l}\text { Ideologia Política (+) } \\
\text { Governo de Coligação (-) } \\
\text { Participação Política (sem } \\
\text { evidências) } \\
\text { Número de Partidos Políticos } \\
\text { (sem evidências) }\end{array}$ \\
\hline $\begin{array}{l}\text { Vicente; Benito; } \\
\text { Bastida } \\
\text { (2013) }\end{array}$ & $\begin{array}{l}97 \text { maiores } \\
\text { municípios } \\
\text { espanhóis } \\
\text { (1999-2009) }\end{array}$ & $\begin{array}{l}\text { Informação recolhida } \\
\text { da Transparência } \\
\text { Internacional Espanha }\end{array}$ & $\begin{array}{l}\text { Gastos Totais (+) } \\
\text { Gastos de Capital (+) } \\
\text { Receita de Impostos (+) } \\
\text { População (+) } \\
\text { Densidade Populacional (+) } \\
\text { Desemprego (+) } \\
\text { Transferências Centrais e Regionais } \\
(+)\end{array}$ & $\begin{array}{l}\text { Ideologia Política (-) } \\
\text { Força Política (+) } \\
\text { Ano Pré-Eleições (+) } \\
\text { Ano Eleições (+) } \\
\text { Ano Pós-Eleições (+) }\end{array}$ \\
\hline $\begin{array}{l}\text { Grimmelikhuijsen; } \\
\text { Welch } \\
(2012)\end{array}$ & $\begin{array}{l}80 \text { municípios } \\
\text { holandeses } \\
(2009)\end{array}$ & $\begin{array}{l}\text { Informação recolhida } \\
\text { dos relatórios de } \\
\text { qualidade do ambiente } \\
\text { disponíveis nas páginas } \\
\text { web dos municípios }\end{array}$ & $\begin{array}{l}\text { Orçamento Ambiental (+) } \\
\text { Presença das Indústrias (+) } \\
\text { Atenção da Mídia (sem evidências) }\end{array}$ & $\begin{array}{l}\text { Grupos de Interesse Ecológico } \\
(+) \\
\text { Representação de Esquerda } \\
\text { (sem evidências) } \\
\text { Competição Política (sem } \\
\text { evidências) }\end{array}$ \\
\hline $\begin{array}{l}\text { Guillamón et al. } \\
\text { (2011) }\end{array}$ & $\begin{array}{l}100 \text { maiores } \\
\text { municípios } \\
\text { espanhóis } \\
(2008)\end{array}$ & $\begin{array}{l}\text { Informação recolhida } \\
\text { da Transparência } \\
\text { Internacional Espanha }\end{array}$ & $\begin{array}{l}\text { População (+) } \\
\text { Receita de Impostos (+) } \\
\text { Transferências Centrais e Regionais } \\
(+) \\
\text { Débito (sem evidências) } \\
\text { Rendimento (sem evidências) } \\
\text { Déficit (sem evidências) }\end{array}$ & $\begin{array}{l}\text { Ideologia Política (+) } \\
\text { Força Política (sem evidências) } \\
\text { Participação Eleitoral (sem } \\
\text { evidências) } \\
\text { Vereadoras no Município } \\
\text { (sem evidências) } \\
\text { Gênero do Presidente do } \\
\text { Município (sem evidências) } \\
\text { Entidades que dependem do } \\
\text { Município (sem evidências) }\end{array}$ \\
\hline
\end{tabular}

Relação entre os fatores e a transparência

2 de 3 
Quadro 1 - Estudos empíricos sobre fatores que influenciam a transparência.

\begin{tabular}{|c|c|c|c|c|}
\hline \multirow{2}{*}{ Autores } & \multirow{2}{*}{ Amostra e período } & \multirow{2}{*}{ Informação } & \multicolumn{2}{|c|}{ Relação entre os fatores e a transparência } \\
\hline & & & Fatores socioeconômicos & Fatores políticos \\
\hline $\begin{array}{l}\text { Pina et al. } \\
(2010)\end{array}$ & $\begin{array}{l}75 \text { municípios de } \\
15 \text { países europeus } \\
\text { (incluindo Portugal) } \\
\text { (2006) }\end{array}$ & $\begin{array}{l}\text { Informação financeira } \\
\text { recolhida nas páginas } \\
\text { web }\end{array}$ & $\begin{array}{l}\text { População (+) } \\
\text { Auditoria da Informação (+) } \\
\text { Estilo de Administração Pública (+) } \\
\text { Orçamento (sem evidências) } \\
\text { Maturidade da Página Web (sem } \\
\text { evidência) } \\
\text { Acesso à Internet (sem evidências) } \\
\text { Corrupção (sem evidências) }\end{array}$ & --- \\
\hline $\begin{array}{l}\text { Gandía; Archidona } \\
\text { (2008) }\end{array}$ & $\begin{array}{l}130 \text { municípios } \\
\text { espanhóis com } \\
\text { mais de } 50.000 \\
\text { habitantes } \\
(2006)\end{array}$ & $\begin{array}{l}\text { Divulgação voluntária } \\
\text { nas páginas web } \\
\text { (informação geral, } \\
\text { informação sobre } \\
\text { orçamento e } \\
\text { informação financeira) }\end{array}$ & $\begin{array}{l}\text { Visibilidade Pública na Mídia (+) } \\
\text { Nível de Educação (+) } \\
\text { Acesso à Internet (+) } \\
\text { Alavanca (sem evidências) } \\
\text { Riqueza do Município (sem } \\
\text { evidências) }\end{array}$ & Competição Política (+) \\
\hline
\end{tabular}

Fonte: Elaborado pelos autores (2020).

Os pesquisadores apontam várias razões para a inconsistência dos resultados, nomeadamente as diferenças no desenho da pesquisa (Alcaide-Muñoz; Rodriguez-Bolivar; Lopez-Hernandez, 2017) e a influência da cultura administrativa de cada país, que pode influenciar o papel do governo e a relação com os cidadãos (Serrano-Cinca; Muñoz-Soro, 2019). Assim, os estudos realizados sobre os fatores influenciadores da transparência sugerem que há similaridades e diferenças entre os estudos, embora os resultados nem sempre sejam similares. Apesar das semelhanças, a forma como cada país implementa e trata a questão da transparência pode variar (Coronel, 2012). Como salienta Meijer (2013), desenvolvimentos sociais similares em diferentes países podem dar lugar a distintos desenvolvimentos políticos que influenciam os níveis de transparência.

Tendo como referencial as pesquisas desenvolvidas e com o objetivo de expandir a pesquisa aos municípios portugueses, este artigo argumenta que a predisposição para a divulgação de informação e a transparência é influenciada por seis fatores: acesso dos cidadãos à Internet, riqueza dos municípios, independência financeira, grau de endividamento dos municípios, participação eleitoral e ideologia política. O estudo examina as variáveis mencionadas porque constituem uma base comum dos modelos utilizados na literatura acadêmica.

No que concerne ao acesso à Internet por parte dos cidadãos, a Internet constitui um potente canal de comunicação e acesso à informação disponibilizada on-line e tem sido amplamente utilizada nos últimos anos pelos governos como instrumento de divulgação da informação (Styles; Tennyson, 2007; Lowatcharin; Menifield, 2015; Piñeiro-Naval; Mangana; Serra, 2018). A Internet é um bom canal de comunicação, pois facilita o acesso à informação para um grande número de utilizadores e satisfaz as necessidades de informação (Pina et al., 2010). Segundo Caba-Pérez, Rodríguez-Bolívar e López-Hernández (2014) e Tejedo-Romero e Araujo (2018), o nível de acesso à Internet é um fator de transparência importante e determinante. O acesso à nternet aumentou a capacidade dos cidadãos de acessar os portais dos municípios e exigir um governo eficiente, responsável e transparente (Gandía; Archidona, 2008; Pina et al., 2010). Espera-se que os cidadãos que utilizam a Internet exerçam maior pressão sobre os funcionários municipais. Portanto, como resposta, os municípios tentarão ser mais transparentes através da divulgação de informação.

Por outro lado, conforme Piotrowski e Van Ryzin (2007) e Piñeiro-Naval, Mangana e Serra (2018), nos municípios mais ricos - aqueles que, através da sua atividade econômica, apresentam um melhor desempenho municipal - e com uma população mais próspera, os cidadãos são mais conscientes das questões da transparência e responsabilidade na gestão dos assuntos locais. É expectável que os cidadãos procurem obter mais informação 
para confirmar se os seus impostos são gastos efetivamente e estejam mais interessados na gestão das finanças locais. Assim, espera-se que, nos municípios com mais riqueza, isso possa significar um sinal de qualidade de gestão que seja benéfico para os políticos locais. A riqueza do município pode melhorar a reputação dos políticos e a possibilidade de reeleição (Gandía; Archidona, 2008). Nesse sentido, admite-se que a riqueza do município aumente a divulgação de informação.

Na mesma perspectiva, a independência financeira - entendida como a capacidade dos municípios de financiar as suas atividades com receitas próprias e sem recorrer a transferências intergovernamentais - desempenha um papel importante na transparência dos municípios e na divulgação de informação (Garrido-Rodríguez; López-Hernández; Zafra-Gómez, 2019). De acordo com Olmo (2018), quanto maior é a proveniência dos recursos financeiros de receitas próprias, maior é a independência financeira dos municípios. Acredita-se que, quanto maior for a independência financeira, mais informações contabilísticas os municípios devem divulgar e mais transparência será necessária para prestar contas aos cidadãos sobre a utilização dos impostos recebidos. Um volume elevado de receitas provenientes de impostos é um incentivo à divulgação de informação financeira para demonstrar a gestão transparente dos recursos recebidos e a atuação correta dos gestores públicos, consoante suas responsabilidades. A transparência das informações financeiras nos portais dos municípios é maior quando existe maior independência financeira.

Também o nível de dívida pública - entendida como todo o financiamento que os municípios obtêm destinado a financiar as suas atividades -, mostra a situação financeira dos municípios e a sua credibilidade em relação aos agentes externos para financiar a prestação de serviços e programas públicos (Caba-Pérez; Rodríguez-Bolívar; López-Hernández, 2014). Em situações de endividamento, os municípios podem usar a divulgação de informação financeira para demonstrar a sua capacidade de cumprir as obrigações financeiras (Garrido-Rodríguez; López-Hernández; Zafra-Gómez, 2019). Em virtude da informação assimétrica, as entidades financiadoras têm dificuldade em determinar com rigor as caraterísticas do risco, o que leva os municípios a usar o aumento da divulgação de informação financeira para reduzir o custo do capital. Para proporcionar sinais positivos sobre o seu desempenho com o objetivo de atrair fundos financeiros, os municípios são incentivados a disseminar informação financeira e assim criar condições para facilitar o monitoramento das suas ações. A divulgação de informação financeira melhora a transparência e mostra aos credores a situação financeira e o risco do município, o que pode influenciar o custo do financiamento proveniente de fontes externas. De acordo com Gandía e Archidona (2008) e Albalate (2013), há uma relação entre os níveis de dívida e o nível de transparência.

Por outra parte, os municípios, enquanto estruturas democráticas que buscam atender às necessidades dos cidadãos, procuram aumentar a participação dos cidadãos nas políticas locais. A preocupação e o envolvimento dos cidadãos na política podem ser expressos pela participação eleitoral. Vários estudos mostram que o envolvimento dos cidadãos e o crescente interesse pelas atividades do governo local são influenciados pelo acesso à informação (Hollyer; Rosendorff; Vreeland, 2011; Caamaño-Alegre et al., 2013). Do mesmo modo, espera-se que haja uma ligação entre transparência e participação eleitoral. Assim, o nível de participação eleitoral pode indicar o interesse pelas atividades do governo local. Igualmente, baixos níveis de participação eleitoral podem significar que os cidadãos têm pouco interesse pelas atividades do governo local. Aumentar os níveis de transparência municipal pode contribuir para a ampliação do envolvimento dos cidadãos na política e o interesse pelas atividades do município, influenciando o nível de participação eleitoral. Esta poderá ser uma forma de legitimar as atividades dos municípios com efeitos positivos na participação eleitoral.

Finalmente, vários estudos mostram que há uma relação entre a ideologia política e a transparência (Balaguer-Coll; Brun-Martos, 2019; Garrido-Rodríguez; López-Hernández; Zafra-Gómez, 2019). Os municípios governados por partidos políticos com uma orientação ideológica de centro-esquerda tendem a revelar mais informação e são mais transparentes que os municípios governados por partidos políticos com uma orientação ideológica de centro-direita (Piotrowski; Van Ryzin, 2007; Guillamón et al., 2011; Albalate, 2013). Uma vez que os 
estudos demonstram (Piotrowski; Van Ryzin, 2007; Guillamón et al., 2011; Albalate, 2013; Tejedo-Romero; Araujo, 2018) que os partidos políticos com uma orientação ideológica de centro-esquerda tendem a defender uma maior intervenção estatal e são mais transparentes, eles divulgam mais informação para justificar as suas escolhas.

Ademais, há outros fatores que necessitam ser considerados e controlados nesta pesquisa, visto que podem ter efeitos sobre os resultados. Segundo as pesquisas realizadas por Vicente, Benito e Bastida (2013) e Cuadrado-Ballesteros (2014), os níveis de transparência podem variar nos períodos eleitorais para que os partidos que estão no governo aumentem a probabilidade de reeleição. Os autores referem, por exemplo, que pode haver manipulação pré-eleitoral da informação relativa aos gastos municipais ou à dívida do município.

\section{A regulação da transparência nos municípios portugueses}

Já em 1989, a Constituição da República Portuguesa estabeleceu o princípio da "Administração Aberta" (n 2 do Art. 268 da Constituição da República Portuguesa), concedendo aos cidadãos o direito de consultar os arquivos e registros administrativos (Portugal, 1989). Esse princípio foi regulado pela Lei no 65/1993, de 26 de agosto, que determinou as condições de acesso a informações administrativas, não obrigando a Administração Pública a divulgar informação sobre as suas atividades. Em 2007, o governo socialista aprovou a Lei no 46/2007, de 24 de agosto, que definiu "o direito de acesso aos documentos administrativos, que inclui os direitos de consulta, reprodução e informação sobre sua existência e conteúdo" (Portugal, 2007, Art. 5, online). A lei não obrigou a Administração Pública a divulgar informação aos cidadãos sobre as suas atividades, porque os partidos de centro-direita recusaram a proposta dos socialistas de incluir na lei a obrigatoriedade de divulgar informações através da Internet de forma completa, organizada e com uma linguagem fácil de entender.

Somente em 2016 o governo socialista, através da Lei no 26/2016, de 22 de agosto, introduziu a divulgação ativa de informações sobre operações e controle de atividades para assegurar a transparência das atividades administrativas. A lei (Art. 10, nº 3) estabeleceu a obrigatoriedade de a Administração Pública divulgar regularmente informação atualizada, em um formato aberto e em termos que permitam o acesso aos conteúdos de forma não condicionada (Portugal, 2016).

\section{Procedimentos Metodológicos}

Esta investigação tem como objetivo analisar a influência de fatores socioeconômicos e políticos na política de transparência ativa nos municípios portugueses. O estudo utiliza um procedimento metodológico baseado na metodologia de dados de painel para obter um modelo de regressão que permita testar empiricamente os fatores que influenciam a divulgação da informação pública, empregando o índice de transparência como um proxy.

Um conjunto de dados é considerado de painel quando se dispõe de uma amostra formada por observações obtidas ao longo do tempo para um agrupamento de municípios portugueses; ou seja, refere-se a dados que combinam uma dimensão temporal (anos) com outra transversal (municípios). Algumas das vantagens em relação a conjuntos de dados de tipo tradicional (séries temporais ou corte transversal) são amplamente conhecidas (Baltagi, 2014; Cuadrado-Ballesteros, 2014). Essa metodologia minimiza possíveis problemas de endogeneidade e melhora a eficiência das estimações econométricas ao capturar a heterogeneidade não observável, quer dos efeitos individuais específicos de cada município, quer dos efeitos temporais de cada um dos anos (Baltagi, 2014; Cuadrado-Ballesteros, 2014). Arapis e Reitano (2018) referem que a análise de dados de painel é necessária para melhorar a compreensão da transparência e a sua evolução no decorrer do tempo.

No desenho desta investigação, foram seguidas as seguintes fases: apresentação da pergunta de investigação e identificação das hipóteses que se pretendem testar, seleção da amostra utilizada no estudo, escolha das variáveis 
para testar as hipóteses e recolher os dados, especificação do modelo empírico e tratamento estatístico dos dados.

Para alcançar o objetivo deste estudo, foi colocada a seguinte pergunta de pesquisa: que fatores influenciam a transparência ativa dos municípios portugueses? A fim de responder a esta pergunta de investigação, formularam-se as seguintes hipóteses de pesquisa: (a) Hipótese 1: Há um efeito positivo entre o nível de transparência dos municípios portugueses e o acesso dos cidadãos à Internet; (b) Hipótese 2: Há um efeito positivo entre o nível de transparência e os municípios portugueses mais ricos; (c) Hipótese 3: Há um efeito positivo entre o nível de transparência e a independência financeira dos municípios portugueses.; (d) Hipótese 4: Há um efeito positivo entre o nível de transparência e o grau de endividamento dos municípios portugueses; (e) Hipótese 5: Há um efeito positivo entre o nível de transparência municipal e a participação eleitoral; (f) Hipótese 6: Há um efeito positivo entre o nível de transparência e os municípios governados por partidos com orientação ideológica de centro-esquerda.

A amostra utilizada para testar as hipóteses compreende a totalidade dos 308 municípios portugueses, para um período de 4 anos - 2013 a 2016 -, durante os quais foram publicados os dados da Transparência e Integridade, Associação Cívica (TIAC), representante português da Transparência Internacional.

\section{Variáveis utilizadas no estudo e procedimento para a coleta de dados}

A variável dependente escolhida foi o índice de transparência dos municípios portugueses (Índice de Transparência), publicado pela Transparência e Integridade (2017). Esse índice é um proxy para medir o nível de transparência dos municípios de acordo com a informação disponível nos portais dos municípios portugueses. O índice tem valores entre 0 e 100. A informação necessária para criar a variável dependente foi tirada do portal da Transparência e Integridade (Transparência e Integridade, 2017).

Para a identificação das variáveis independentes, selecionamos as seguintes variáveis que podem influenciar o nível de transparência:

a) Acesso à Internet: Variável numérica calculada com base no total de acessos residenciais ao serviço de Internet de banda larga dividido pela densidade populacional.

b) Municípios Ricos: Variável numérica representada pelo índice de desempenho municipal como um proxy dos municípios mais ricos. Essa variável é calculada segundo indicadores relacionados com o crescimento regional e está disponível na base de dados Sales Index Marktest.

c) Independência Financeira: Variável numérica que representa a relação entre a receita de fontes próprias dos municípios e o total das receitas efetivas. As receitas de fontes próprias correspondem à soma das receitas fiscais (impostos diretos, impostos indiretos, taxas, multas e outras penalidades), receitas de vendas de bens e serviços, receitas de imóveis e vendas de imóveis de investimento. O total das receitas efetivas corresponde à receita total menos os ativos e passivos financeiros.

d) Grau de Endividamento: Variável numérica que representa a proporção da dívida total dos municípios e da receita efetiva. A dívida inclui informação sobre empréstimos, contratos de locação financeira e outras dívidas a terceiros resultantes das operações do orçamento. Foi incluída neste valor a dívida bruta dos serviços municipalizados, entidades associativas municipais, empresas municipais e intermunicipais e entidades participadas, quando estas se encontrem em situação de desequilíbrio financeiro. A receita efetiva corresponde ao total da receita menos os ativos e passivos financeiros.

e) Participação Eleitoral: Variável numérica que representa a percentagem de participação dos cidadãos nas últimas eleições autárquicas. 
f) Ideologia Política: Variável dummy que assume o valor de 1 se o presidente da Câmara Municipal pertence a um partido de orientação ideológica de centro-esquerda e o valor de 0 se a orientação ideológica é de centrodireita.

Quanto à identificação das variáveis de controle, para evitar resultados enviesados, foi controlado o efeito do período eleitoral, uma vez que este pode influenciar o nível de transparência dos municípios. De acordo com Vicente, Benito e Bastida (2013) e Cuadrado-Ballesteros (2014), a manipulação pré-eleitoral dos gastos municipais ou dos déficits pode impactar nos níveis de transparência, de forma a que os partidos políticos no poder aumentem a probabilidade de reeleição. Foram consideradas as seguintes variáveis:

a) Pré-eleição: Variável dummy que assume o valor de 1 no ano anterior às eleições autárquicas e de 0 caso contrário.

b) Eleição: Variável dummy que assume o valor de 1 no ano de eleições autárquicas e de 0 caso contrário.

c) Pós-eleição: Variável dummy que assume o valor de 1 no ano após as eleições autárquicas e de 0 caso contrário.

Os dados das variáveis independentes e de controle foram recolhidos da publicação anual "Finanças Municipais" da Direção Geral de Autarquias Locais, da Comissão Nacional de Eleições, do Instituto Nacional de Estatística e da base de dados de indicadores da Sales Index Marktest. Para o ano de 2013, os dados foram recolhidos dos resultados das eleições autárquicas de novembro de 2009. Para os anos de 2014, 2015 e 2016, os dados foram recolhidos dos resultados das eleições autárquicas de novembro de 2013.

Finalmente, um conjunto de dados de painel não balanceado foi adotado, com um total de 1.098 observações. Podem-se classificar os dados de painel como balanceados, quando não há observações perdidas (missing values), e como não balanceados, quando não se observam algumas unidades ou indivíduos em alguns períodos. Os dados são geralmente coletados ao longo do tempo (anos), envolvendo os mesmos indivíduos (municípios), e, em seguida, uma regressão é executada sobre essas duas dimensões (Baltagi, 2014).

Foi adotado o método de regressão de dados de painel não balanceado testado empiricamente através de regressões de Prais-Winsten com erros-padrão corrigidos pelo painel. A estatística descritiva das variáveis utilizadas no painel de dados aparece compilada na Tabela 1.

\section{Resultados}

Esta seção apresenta os resultados empíricos do estudo utilizando análises multivariadas. Para evitar a influência de outliers, foi realizada a winsorização das variáveis contínuas - Acesso à Internet, Municípios Ricos, Independência Financeira e Grau de Endividamento - para os 5\% do percentil superior e inferior da distribuição.

A Tabela 2 exibe a regressão dos dados de painel. Foram corrigidas a dependência transversal e a heterocedasticidade por grupos e erros de ordem 1 ao estimar as regressões de Prais-Winsten com erros-padrão corrigidos pelo painel.

Os resultados finais obtidos mostram que a variável Acesso à Internet tem uma relação positiva e significativa com a transparência para um nível de significância de $1 \%(\beta 1=0,0840)$. Isso confirma que o acesso à Internet é um fator importante para a transparência, uma vez que aumenta a capacidade dos cidadãos de acessar o portal dos municípios para consultar informações. Pese embora as pesquisas sobre os municípios portugueses não tenham utilizado essa variável (Quadro 1), os resultados são consistentes com trabalhos anteriores de Gandía e Archidona (2008), Caba-Pérez, Rodríguez-Bolívar e López-Hernández (2014) e Tejedo-Romero e Araujo (2018). Aceitamos a hipótese 1. 
Tabela 1 - Estatística descritiva das variáveis.

\begin{tabular}{|c|c|c|c|c|c|c|c|c|c|c|}
\hline Parte A: Variáveis Contínuas & & 13 & \multicolumn{2}{|c|}{2014} & \multicolumn{2}{|c|}{2015} & \multicolumn{2}{|c|}{2016} & \multicolumn{2}{|c|}{ 2013-2016 } \\
\hline \multicolumn{11}{|l|}{ Transparência } \\
\hline Média & & 33,70 & \multicolumn{2}{|c|}{34,50} & \multicolumn{2}{|c|}{45,10} & \multicolumn{2}{|c|}{53,20} & \multicolumn{2}{|c|}{41,06} \\
\hline Desvio-Padrão & & 9,54 & \multicolumn{2}{|c|}{12,00} & \multicolumn{2}{|c|}{16,90} & \multicolumn{2}{|c|}{19,60} & \multicolumn{2}{|c|}{17,00} \\
\hline Máximo & & 51,00 & \multicolumn{2}{|c|}{81,60} & \multicolumn{2}{|c|}{94,20} & \multicolumn{2}{|c|}{100,00} & \multicolumn{2}{|c|}{100,00} \\
\hline Mínimo & & 7,00 & \multicolumn{2}{|c|}{3,20} & \multicolumn{2}{|c|}{7,97} & \multicolumn{2}{|c|}{16,20} & \multicolumn{2}{|c|}{3,02} \\
\hline Acesso à Internet & & & & & & & & & & \\
\hline Média & & 0434 & & & 0,0 & & & & & 516 \\
\hline Desvio-Padrão & & 0385 & & & & & & & & 423 \\
\hline Máximo & & 0,166 & & & & & & & & 166 \\
\hline Mínimo & & 0913 & & & 0,00 & & 0,00 & & & 913 \\
\hline Municípios Ricos & & & & & & & & & & \\
\hline Média & & 0,287 & & 81 & & & & & & 284 \\
\hline Desvio-Padrão & & 0,343 & & & & & & & & 344 \\
\hline Máximo & & 1,29 & & 29 & & & & & & 1,29 \\
\hline Mínimo & & 0,035 & & & & & & & & 035 \\
\hline Independência Financeira & & & & & & & & & & \\
\hline Média & & 37,40 & & & & & & & & 9,70 \\
\hline Desvio-Padrão & & 15,90 & & & & & & & & 6,60 \\
\hline Máximo & & 73,60 & & & & & & & & 3,60 \\
\hline Mínimo & & 6,80 & & & & & & & & 6,80 \\
\hline Grau de Endividamento & & & & & & & & & & \\
\hline Média & & 46,00 & & & & & & & & 4,80 \\
\hline Desvio-Padrão & & 49,80 & & & & & & & & 3,10 \\
\hline Máximo & & 6,00 & & & & & & & & 6,00 \\
\hline Mínimo & & 0,785 & & & & & & & & 785 \\
\hline Participação Eleitoral & & & & & & & & & & \\
\hline Média & & 63,40 & & & & & & & & 0,10 \\
\hline Desvio-Padrão & & 7,630 & & 07 & & & & & & 970 \\
\hline Máximo & & 81,10 & & & & & & & & 1,40 \\
\hline Mínimo & & 38,90 & & & & & & & & 7,80 \\
\hline Parte B: Variáveis Dummies & & 13 & & & & & & & 201 & 2016 \\
\hline & 0 & 1 & 0 & 1 & 0 & 1 & 0 & 1 & 0 & 1 \\
\hline Ideologia & & & & & & & & & & \\
\hline Frequência & 122,0 & 152,0 & 103,0 & 170,0 & 106,0 & 172,0 & 105,0 & 168,0 & 436,0 & 662,0 \\
\hline Percentagem & 44,5 & 55,5 & 37,7 & 62,3 & 38,1 & 61,9 & 38,5 & 61,5 & 39,7 & 60,3 \\
\hline Pré-Eleição & & & & & & & & & & \\
\hline Frequência & 274,0 & 0,0 & 273,0 & 0,0 & 278,0 & 0,0 & 0,0 & 273,0 & 825,0 & 273,0 \\
\hline Percentagem & 100,0 & 0,0 & 100,0 & 0,0 & 100,0 & 0,0 & 0,0 & 100,0 & 75,0 & 25,0 \\
\hline Eleição & & & & & & & & & & \\
\hline Frequência & 0,0 & 274,0 & 273,0 & 0,0 & 278,0 & 0,0 & 273,0 & 0,0 & 824,0 & 274,0 \\
\hline Percentagem & 0,0 & 100,0 & 100,0 & 0,0 & 100,0 & 0,0 & 100,0 & 0,0 & 75,0 & 25,0 \\
\hline Pós-Eleição & & & & & & & & & & \\
\hline Frequência & 274,0 & 0,0 & 0,0 & 273,0 & 278,0 & 0,0 & 273,0 & 0,0 & 825,0 & 273,0 \\
\hline Percentagem & 100,0 & 0,0 & 0,0 & 100,0 & 100,0 & 0,0 & 100,0 & 0,0 & 75,0 & 25,0 \\
\hline N (observações) & & 4 & & & & & & & & \\
\hline
\end{tabular}

Fonte: Elaborado pelos autores (2019).

As variáveis Municípios Ricos e Independência Financeira não foram significativas $(\beta 2=0,1125 ; \beta 3=0,1125$, respectivamente). Esses resultados são similares aos estudos realizados nos municípios espanhóis por Gandía e Archidona (2008) e Guillamón et al. (2011), que não encontraram uma relação significativa entre os Municípios 
Tabela 2 - Modelo de regressão de painel.

\begin{tabular}{ll}
\hline Variáveis independentes e de controle & Transparência \\
\hline Acesso à Internet & $0,0840^{* * *}$ \\
Municípios Ricos & $(0,0287)$ \\
Independência Financeira & 0,1125 \\
& $(0,1425)$ \\
Grau de Endividamento & 0,1125 \\
& $(0,0010)$ \\
Participação Eleitoral & $0,0003^{* * *}$ \\
& $(0,0001)$ \\
Ideologia Política & $-0,0029^{* * *}$ \\
& $(0,0011)$ \\
Pré-Eleição & $0,0373^{* * *}$ \\
Eleição & $(0,0106)$ \\
Pós-Eleição & $0,0720^{* * *}$ \\
(Constante) & $(0,0063)$ \\
\hline Observações & $-0,0647^{* * *}$ \\
R2 & $(0,0067)$ \\
Wald chiz(9) & $-0,1062^{* * *}$
\end{tabular}

Nota: Os números entre parênteses representam os valores dos erros-padrão. Os asteriscos representam o nível de significação das variáveis: ${ }^{* * *}$ para um nível de significação de 1\%. Foi utilizado o índice de transparência em uma escala de 0-1. A transformação do logaritmo é usada para a variável Acesso à Internet. Fonte: Elaborado pelos autores (2019).

Ricos e a Transparência. Por outro lado, Gesuele et al. (2018) não constataram uma relação significativa entre a Independência Financeira e a Transparência em uma amostra de municípios italianos e espanhóis. Contudo, Tavares e Cruz (2020) e Piñeiro-Naval, Mangana e Serra (2018) verificaram uma relação positiva para o caso dos municípios portugueses (Quadro 1). A hipótese 2 e a hipótese 3 não são confirmadas.

No caso da variável Grau de Endividamento, existe uma relação positiva e significativa com a transparência para um nível de significância de 1\% $(\beta 4=0,0003)$. Isso revela que um nível mais elevado de endividamento do município contribui para o incremento do nível de transparência, funcionando como um mecanismo que permite monitorizar a situação financeira dos municípios. Apesar de as pesquisas sobre os municípios portugueses não terem utilizado essa variável (Quadro 1), os resultados são consistentes com os trabalhos anteriores de Gandía e Archidona (2008), Albalate (2013) e Caamaño-Alegre et al. (2013). Confirma-se a hipótese 4.

Em relação à variável Participação Eleitoral, ela é significativa para um nível de significância de 1\% e negativamente associada à transparência $(\beta 5=-0,0029)$. A baixa participação eleitoral pode indicar menor confiança dos cidadãos no governo municipal. Assim, o nível de participação eleitoral pode contribuir para o aumento da transparência municipal. Embora as pesquisas sobre os municípios portugueses não tenham utilizado essa variável (Quadro 1), esse resultado é consistente com o trabalho de Fung (2013) e suporta a hipótese 5.

Observa-se que a Ideologia Política está positivamente correlacionada com a transparência ao nível de significância de 1\% ( $\beta 6=0,0373)$. Esses dados sugerem que os municípios governados por partidos de centro-esquerda são mais transparentes do que os municípios governados por partidos de centro-direita. No caso da pesquisa realizada por Tavares e Cruz (2020) para os municípios portugueses, não foram encontradas evidências dessa relação. No entanto, esses resultados são consistentes com trabalhos anteriores (Guillamón et al., 2011; Albalate, 
2013; Caamaño-Alegre et al., 2013; Tejedo-Romero; Araujo, 2018), que identificaram uma relação positiva com o índice de transparência em municípios governados por partidos de centro-esquerda. Esse resultado suporta a hipótese 6.

Em relação às variáveis de controle, foi analisada a influência do período eleitoral na transparência. Os resultados mostram que os anos pré-eleitorais estão positivamente correlacionados com a transparência ao nível de significância de 1\% ( $\beta 7=0,0720)$. Isso sugere que os municípios tendem a ser mais transparentes no ano anterior às eleições, eventualmente para mostrar a boa utilização dos recursos e a sua competência na gestão das questões relacionadas com a vida dos cidadãos e dos recursos recebidos (Cuadrado-Ballesteros, 2014). Por outro lado, aponta uma preocupação dos políticos locais em demonstrar aos cidadãos que, durante o seu mandato, agiram de acordo com suas responsabilidades, procurando assim influenciar as decisões dos eleitores. Contudo, os resultados denotam que os anos de eleição e após a eleição estão negativamente correlacionados com a Transparência, com um nível de significância de $1 \%$ ( $\beta 8=-0,0647 ; \beta 9=-0,1062$, respectivamente).

\section{Discussão e Conclusão}

O principal objetivo deste artigo foi identificar os fatores socioeconômicos e políticos que influenciaram o nível de transparência dos municípios portugueses. No que concerne aos fatores socioeconômicos - acesso à Internet, municípios ricos, independência financeira e grau de endividamento -, observa-se que as variáveis Acesso à Internet e Grau de Endividamento tiveram um efeito positivo e significativo no nível de transparência ativa nos municípios portugueses.

O acesso à Internet pode contribuir para o aumento da capacidade dos cidadãos de entrar no portal dos municípios, facilitando o acesso à informação e contribuindo para o aumento da transparência. Esse resultado é consistente com as conclusões das pesquisas realizadas por Gandía e Archidona (2008), Pina et al. (2010), CabaPérez, Rodríguez-Bolívar e López-Hernández (2014) e Tejedo-Romero e Araujo (2018). O acesso à Internet pode ser uma oportunidade para interação maior entre os cidadãos e os municípios através das redes sociais, funcionando como um mecanismo para maior pressão sobre a transparência municipal. Assim, espera-se que, quanto maior a discussão nas redes sociais sobre a gestão dos municípios, mais pressão existirá para informar os cidadãos sobre as decisões tomadas. Essa questão, que não foi objeto de análise neste estudo, poderá ser objeto de pesquisas futuras.

Finalmente, os municípios com elevado grau de endividamento apresentaram níveis de transparência mais elevados. A divulgação de informação financeira aumenta a transparência sobre a situação financeira dos municípios e pode contribuir para melhorar a sua credibilidade. Esses resultados corroboram outras pesquisas (Gandía; Archidona, 2008; Albalate, 2013; Caamaño-Alegre et al., 2013; Garrido-Rodríguez; López-Hernández; Zafra-Gómez, 2019) que encontraram uma relação entre o grau de endividamento dos municípios (dívida) e o nível de transparência. Esses autores salientam a importância da transparência para comprovar a capacidade de cumprimento das obrigações financeiras dos municípios e demonstrar aos agentes externos a competência de cumprir as obrigações financeiras para reduzir os custos de financiamento. Um nível mais elevado de transparência pode mostrar a situação financeira dos municípios e a sua credibilidade em relação aos agentes externos (CabaPérez; Rodríguez-Bolívar; López-Hernández, 2014) para financiar a prestação de serviços e programas públicos. No que se refere aos municípios ricos e à independência financeira, assim como foi encontrado em outras pesquisas (Guillamón et al., 2011; Albalate, 2013; Gesuele et al., 2018), esses fatores não influenciam significativamente os níveis de transparência municipal. Talvez esses fatores não sejam suficientes para provocar mudanças que pressionem os municípios a melhorar o seu nível de transparência.

Da análise dos fatores políticos, observa-se que as variáveis consideradas no estudo - participação eleitoral, ideologia e período eleitoral - tiveram um efeito significativo no nível de transparência dos municípios portugueses. 
Desse modo, nos municípios onde a participação eleitoral foi menor, houve mais divulgação de informação. Esse resultado indica que, na tentativa de aumentar a participação eleitoral dos cidadãos nas eleições autárquicas, os responsáveis políticos locais procuraram divulgar mais informação e ser mais transparentes para assim obter o apoio dos cidadãos através da participação eleitoral. É razoável admitir que, para poder aumentar o envolvimento e a participação dos cidadãos nos processos eleitorais e recuperar a confiança deles no funcionamento dos municípios, estes divulguem mais informações sobre o orçamento, planos e atividades. O aumento da divulgação de informação sobre as decisões, os processos e o funcionamento dos municípios potencialmente contribui para o aumento da confiança dos cidadãos, funcionando como um incentivo positivo para o apoio dos cidadãos nas futuras eleições. Esta é uma questão que poderá ser aprofundada em pesquisas futuras.

De acordo com as pesquisas realizadas por Hollyer, Rosendorff e Vreeland (2011), Caamaño-Alegre et al. (2013) e Fung (2013), os interesses dos cidadãos pelas atividades do governo local são influenciados pela facilidade de acesso à informação. Trata-se de uma estratégia que os políticos no poder por vezes utilizam para obter a simpatia dos eleitores e conseguirem a reeleição através do aumento da participação eleitoral e de melhores resultados nas eleições municipais.

Além disso, os resultados sugerem que a ideologia política impactou no nível de transparência. Esses resultados são corroborados por outros estudos, que identificam uma relação similar (Balaguer-Coll; Brun-Martos, 2019; Garrido-Rodríguez; López-Hernández; Zafra-Gómez, 2019). Os resultados obtidos neste estudo apontam que os municípios cujo governo é constituído por partidos com ideologia de centro-esquerda têm níveis de transparência mais elevados quando comparados com os municípios governados por partidos de centro-direita. Esses resultados são similares aos encontrados nas pesquisas realizadas por Piotrowski e Van Ryzin (2007), Guillamón et al. (2011), Albalate (2013) e Tejedo-Romero e Araujo (2018).

Por outro lado, os resultados estão em linha com o que foi analisado neste estudo relativamente às iniciativas legislativas sobre a política de transparência. As propostas legislativas apresentadas pelos partidos de centro-esquerda foram mais favoráveis à divulgação ativa de informação pública. Assim, os dados sugerem que os partidos de centro-esquerda são mais receptivos a questões de transparência do que os partidos de centro-direita.

Por fim, os resultados denotam a importância que a transparência pode ter nos períodos eleitorais. Esses resultados indicam a influência do período eleitoral na divulgação de informação, confirmando as conclusões das pesquisas de Vicente, Benito e Bastida (2013) e Cuadrado-Ballesteros (2014). Esses autores referem que a manipulação pré-eleitoral dos gastos municipais ou dos déficits pode influenciar os níveis de transparência, de forma a que os partidos políticos no poder aumentem a probabilidade da sua reeleição. Após as eleições, as pressões para os municípios divulgarem informação e serem mais transparentes tendem a diminuir, porque um novo ciclo político começa. A principal lição desta pesquisa é que a transparência e o intercâmbio de informação entre municípios e cidadãos são influenciados principalmente por fatores políticos.

Este estudo é uma contribuição para a literatura sobre a divulgação de informação e acesso à informação dos municípios, pois ajuda a compreender a transparência em relação à informação pública. Ele auxilia a preencher a lacuna na literatura sobre transparência, com a intenção de enriquecer o debate sobre os efeitos que os fatores socioeconômicos e políticos podem ter sobre esta, analisando um contexto pouco estudado. Os resultados estendem as pesquisas existentes sobre os determinantes que afetam a transparência, sinalizando a importância que os períodos eleitorais podem ter no estudo desse fenômeno. Os resultados potencialmente ajudam os decisores políticos e os governos locais sobre as ações necessárias para aumentar a transparência ativa dos municípios.

Uma vez que a Internet é um fator influenciador da transparência, devem ser tomadas medidas para aumentar o acesso dos cidadãos à Internet e reduzir a infoexclusão. Por outro lado, os municípios devem ser encorajados a utilizar a Internet para abrir novos canais de comunicação e assim melhorar a divulgação de informação e a transparência. Para os decisores políticos, esta pesquisa oferece orientações e identifica alguns fatores que podem influenciar os níveis de transparência. 
Esta pesquisa apresenta algumas limitações, nomeadamente porque não considera outros fatores como, por exemplo, culturais e tecnológicos; não analisa como os cidadãos percebem a informação, o que poderia ajudar a compreensão da transparência; e não analisa a influência das redes sociais. Por fim, este estudo só considera um período de 4 anos, o que limita a utilização de outros modelos estatísticos. Futuras investigações devem analisar períodos mais longos, recorrendo a outros métodos estatísticos, e devem examinar a influência de outros fatores, como os culturais, demográficos e tecnológicos na transparência municipal.

\section{Colaboradores}

F. TEJEDO-ROMERO contribuiu com a coleta dos dados, a análise empírica e a interpretação dos dados. J. F. F. E. ARAUJO contribuiu com a revisão da literatura e a discussão dos resultados.

\section{Referências}

Albalate, D. The institutional, economic and social determinants of local government transparency. Journal of Economic Policy Reform, v. 16, n. 1, p. 90-107, 2013. Doi: https:// doi.org/10.1080/17487870.2012.759422.

Alcaide-Muñoz, L.; Rodriguez-Bolivar, M. P.; LopezHernandez, A. M. Transparency in governments: a metaanalytic review of incentives for digital versus hard-copy public financial disclosures. American Review of Public Administration, v. 47, n. 5, p. 550-573, 2017. Doi: https://doi. org/10.1177/0275074016629008.

Arapis, T.; Reitano, V. Examining the evolution of crossnational fiscal transparency. American Review of Public Administration, v. 48, n. 6, p. 550-564, 2018. Doi: https://doi. org/10.1177/0275074017706740.

Balaguer-Coll, M. T.; Brun-Martos, M. I. The effects of the political environment on transparency: evidence from Spanish local governments. Policy Studies, p. 1-22, 2019. Doi: https://doi.org/10.1080/01442872.2019.1599838.

Baltagi, B. Econometric analysis of panel data. London: Wiley, 2014.

Bauhr, M.; Grimes, M. Indignation or resignation: the implications of transparency for societal accountability. Governance, v. 27, n. 2, p. 291-320, 2014. Doi: https://doi. org/10.1111/gove.12033.

Beltrán-Orenes, P.; Martínez-Pastor, E. Grado de cumplimiento de las leyes de transparencia, acceso y buen gobierno, y de reutilización de los datos de contratación de la Administración central Española. El Profesional de la Información, v. 25, n. 4, p. 557-567, 2016. Doi: https://doi.org/10.3145/epi.2016.jul.05.

Birchall, C. Data. gov-in-a-box' Delimiting transparency. European Journal of Social Theory, v. 18, n. 2, p. 185-202, 2015. Doi: https://doi.org/10.1177/1368431014555259.

Brusca, I.; Manes, F.; Aversano, N. Online sustainability information in local governments in an austerity context: an empirical analysis in Italy and Spain. Online Information Review, v. 40, n. 4, p. 497-514, 2016. Doi: https://doi.org/10.1108/OIR05-2015-0161.
Caamaño-Alegre, J. et al. Budget transparency in local governments: an empirical analysis. Local Government Studies, v. 39, n. 2, p. 182-207, 2013. Doi: https://doi.org/10.2139/ ssrn.1768091.

Caba-Pérez, M. C.; Rodríguez-Bolívar, M. P.; López-Hernández, A. M. The determinants of government financial reports online. Transylvanian Review of Administrative Sciences, v. 10, n. 42, p. 5-31, 2014.

Coronel, S. Measuring openness: a survey of transparency ratings and the prospects for a global index. Freedominfo. org, Washington, Oct, 30, 2012. Available from: http://www. freedominfo.org/2012/10/measuring-openness-a-survey-oftransparency-ratings-and-the-prospects-for-a-global-index/. Cited: Jan. 17, 2018.

Cuadrado-Ballesteros, B. The impact of functional decentralization and externalization on local government transparency. Government Information Quarterly, v. 31, n. 2, p. 265-277, 2014. Doi: https://doi.org/10.1016/j.giq.2013.10.012.

Cucciniello, M.; Porumbescu, G. A.; Grimmelikhuijsen, S. 25 years of transparency research: evidence and future directions. Public Administration Review, v. 77, n. 1, p. 32-44, 2017. Doi: https://doi.org/10.1111/puar.12685.

Curto-Rodríguez, R. Transparencia operativa de las comunidades autónomas españolas mediante sus portales de datos abiertos. El Profesional de la Información, v. 29, n. 1, p. 242-261, 2020. Doi: https://doi.org/10.3145/epi.2020.ene.15.

Fung, A. Infotopia: unleashing the democratic power of transparency. Politics and Society, v. 41, n. 2, p. 183-212, 2013. Doi: https://doi.org/10.1177/0032329213483107.

Gandía, J. L.; Archidona, M. C. Determinants of web site information by Spanish city councils. Online Information Review, v. 32, n. 1, p. 35-57, 2008. Doi: https://doi. org/10.1108/14684520810865976.

García-Tabuyo, M.; Saez-Martin, A.; Caba-Perez, C. Proactive disclosure of public information: legislative choice worldwide. Online Information Review, v. 41, n. 3, p. 354-377, 2017. Doi: https://doi.org/10.1108/OIR-02-2016-0054. 
Garrido-Rodríguez, J. C.; López-Hernández, A. M.; Zafra-Gómez, J. L. The impact of explanatory factors on a bidimensional model of transparency in Spanish local government. Government Information Quarterly, v. 36, n. 1, p. 154-165, 2019. Doi: https://doi.org/10.1016/j.giq.2018.10.010.

Gesuele, B. et al. The determinants of e-disclosure attitude: empirical evidences from Italian and Spanish municipalities. International Journal of Public Administration, v. 41, n. 11, p. 921-934, 2018. Doi: https://doi.org/10.1080/01900692.2017.1 300917.

Grimmelikhuijsen, S.; Welch, E. W. Developing and testing a theoretical framework for computer-mediated transparency of local governments. Public Administration Review, v. 72, n. 4, p. 562-571, 2012. Doi: https://doi.org/10.1111/j.15406210.2011.02532.x.

Guillamón, M. D. et al. The determinants of local governments' financial transparency. Local Government Studies, v. 37, n. 4, p. 391-406, 2011. Doi: https://doi.org/10.1080/03003930.2011.5 88704.

Hollyer, J. R.; Rosendorff, B. P.; Vreeland, J. R. Democracy and transparency. The Journal of Politics, v. 73, n. 4, p. 1191-1205, 2011. Doi: https://doi.org/10.1017/S0022381611000880.

Lowatcharin, G.; Menifield, C. E. Determinants of Internetenabled transparency at the local level: a study of Midwestern county web sites. State and Local Government Review, v. 47, n. 2, p. 102-115, 2015. Doi: https://doi. org/10.1177/0160323×15593384.

Manfredi-Sánchez, J. L. Horizontes de la información pública. El Profesional de la Información, v. 26, n. 3, p. 353-360, 2017. Doi: https://doi.org/10.3145/epi.2017.may.01.

Meijer, A. Understanding the complex dynamics of transparency. Public Administration Review, v. 73, n. 3, p. 429-439, 2013. Doi: https://doi.org/10.1111/puar.12032.

Mendes, H. C. et al. Local authorities and the disclosure of financial information via the internet: the portuguese case. In: Ferreira, A. et al. (ed.). Global perspectives on risk management and accounting in the public sector. Hershey: IGI Global, 2016. p. 274-295. Doi: https://doi.org/10.4018/978-1-4666-9803-1. ch014.

Moreno-Sardà, A.; Molina-Rodríguez-Navas, P.; Simelio-Solà, N. Impacto de la legislación sobre transparencia en la información publicada por las administraciones locales. El Profesional de la Información, v. 26, n. 3, p. 370-380, 2017. Doi: https://doi.org/10.3145/epi.2017.may.03.

Navarro, A.; Alcaraz, F. J.; Ortiz, D. Enhancing sustainability transparency in local governments: an empirical research in Europe. Sustainability, v. 10, n. 7, p. 1-22, 2018. Doi: https://doi. org/10.3390/su10072161.

Olmo, J. Explanatory factors and limitations of Spanish local debt. Revista Latinoamericana de Administración, v. 31, n. 2, p. 360-377, 2018. Doi: https://doi.org/10.1108/arla-12-20150330.

Pina, V. et al. Is e-government promoting convergence towards more accountable local governments? International Public Management Journal, v. 13, n. 4, p. 350-380, 2010. Doi: https://doi.org/10.1080/10967494.2010.524834.
Piñeiro-Naval, V.; Mangana, R.; Serra, P. Validación del Índice de Calidad Formal como modelo para la evaluación de websites: el caso de la e-Administración local portuguesa. Transinformação, v. 30, n. 2, p. 153-165, 2018. Doi: http:// dx.doi.org/10.1590/2318-08892018000200002.

Piotrowski, S. J. Governmental transparency in the path of administrative reform. New York: State University of New York Press, 2007.

Piotrowski, S. J.; Van Ryzin, G. G. Citizen attitudes toward transparency in local government. The American Review of Public Administration, v. 37, n. 3, p. 306-323, 2007. Doi: https:// doi.org/10.1177/0275074006296777.

Portugal. Lei Constitucional no 1/89. Segunda revisão da Constituição. Diário da República. Lisboa: Presidência da República, 1989. Disponível em: https://dre.pt/home/-/ dre/496551/details/maximized. Acesso em: 17 jan. 2018.

Portugal. Lei no 65/93, de 26 de agosto de 1993. Regula o acesso aos documentos da Administração. Diário da República. Lisboa: Presidência da República, 1993. Disponível em: https:// dre.pt/pesquisa/-/search/632408/details/maximized. Acesso em: 17 jan. 2018.

Portugal. Lei no 46/2007, de 24 de agosto de 2007. Regula o acesso aos documentos administrativos e a sua reutilização. Diário da República. Lisboa: Presidência da República, 2007. Disponível em: https://dre.pt/web/guest/pesquisa/-/ search/640919/details/normal?q=Lei+n.\%C2\%BA\%20 46\%2F2007\%2C\%20de+24+de+Agosto. Acesso em: 17 jan. 2018.

Portugal. Lei no 26/2016, de 22 de agosto de 2016. Aprova o regime de acesso à informação administrativa e ambiental e de reutilização dos documentos administrativos. Diário da República. Lisboa: Presidência da República, 2016. Disponivél em: https://dre.pt/web/guest/pesquisa/-/search/75177807/ details/normal?q=Lei+n.\%C2\%BA\%2026\%2F2016\%2C\%20 de+22+de+agosto+. Acesso em: 17 jan. 2018.

Rebolledo, M.; Zamora-Medina, R.; Rodríguez-Virgili, J. Transparency in citizen participation tools and public information: a comparative study of the Spanish city councils' websites. El Profesional de la Información, v. 26, n. 3, p. 361-369, 2017. Doi: https://doi.org/10.3145/epi.2017.may.02.

Robles-López, C. M.; Zamora-Medina, R. Transparencia online como bien intangible del sector público. Transinformação, v. 32, e190059, 2020. Doi: https://doi.org/10.1590/1678$9865202032 \mathrm{e} 190059$.

Serrano-Cinca, C.; Muñoz-Soro, J. F. What municipal websites supply and citizens demand: a search engine optimisation approach. Online Information Review, v. 43, n. 1, p. 7-28, 2019. Doi: https://doi.org/10.1108/OIR-02-2018-0042.

Styles, A. K.; Tennyson, M. The accessibility of financial reporting of US municipalities on the Internet. Journal of Public Budgeting, Accounting and Financial Management, v. 19, n. 1, p. 56-92, 2007. Doi: https://doi.org/10.1108/jpbafm-1901-2007-b003.

Tavares, A. F.; Cruz, N. F. Explaining the transparency of local government websites through a political market framework. 
Government Information Quarterly, v. 37, n. 3, 2020. Doi: https:// doi.org/10.1016/j.giq.2017.08.005.

Tejedo-Romero, F.; Araujo, J. F. F. E. Transparencia en los municipios españoles: determinantes de la divulgación de información. Convergencia, v. 25, n. 78, p. 153-174, 2018. Doi: https://doi.org/10.29101/crcs.v25i78.9254.

Transparência e Integridade. Índice de Transparência Municipal. Lisboa: Transparência e Integridade, 2017. Disponível em: https://transparencia.pt/itm/. Acesso em: 17, jan. 2018.
Vicente, C.; Benito, B.; Bastida, F. Transparency and political budget cycles at municipal level. Swiss Political Science Review, v. 19, n. 2, p. 139-156, 2013. Doi: https://doi.org/10.1111/ spsr.12036.

Wasike, B. FOI in transition: a comparative analysis of the Freedom of Information Act performance between the Obama and Trump administrations. Government Information Quarterly, v. 37, n. 2, e101443, 2020. Doi: https://doi. org/10.1016/j.giq.2019.101443. 